\title{
EXTRACURRICULAR ACTIVITIES IN PHYSICAL EDUCATION AND SPORTS AT SCHOOL IN THE COVID-19 CONDITIONS
}

\author{
Mariana Borukova, Milena Kuleva \\ National Sports Academy "Vassil Levski" (Bulgaria)
}

\begin{abstract}
In the educational system of Bulgaria, extracurricular activities are provided and organized in all schools. There are also schools in the education system of Bulgaria that are neither private nor attached to the Ministry of Education. They are foreign schools in Bulgaria that are under the auspices of their embassies and their education system (e.g. French Lyceum, Anglo-American School, Russian School, American College and others). Sports activities are widespread, as it is well known that most European countries, and especially the United States, believe that competitive spirit is crucial in many professional fields, as well as teamwork, which is imperceptibly developing in most sports. The aim of the present study is to examine the opinion of parents of children from the secondary education level regarding extracurricular activities in physical education and sports in the context of COVID-19. Various research methods were used, like review study of specialized literature and normative documents and survey method. As a result, it was concluded that when students are placed in new and different conditions for sports, their desire and interest to play and to be active is not reduced. The created and well-organized safe environment during the classes gives confidence and peace of mind to the parents that their children are safe

Keywords: extracurricular activities; children; anti-epidemic measures; sports
\end{abstract}

\section{Introduction}

The COVID-19 pandemic has created a number of problems worldwide, which in addition to the health system affected many other areas. One of these areas is the education system, which was necessary to adapt to the epidemiological situation in each of the countries around the world. This includes extracurricular school activities. As regards social psychic health, the major psychological consequences now are related to increased stress, anxiety, and depression. (Iancheva, Rogaleva, García-Mas \& Olmedilla 2020)

In the educational system of Bulgaria, extracurricular activities are provided and organized in all schools. In 2019, REGULATION № 24 of 05.11.2019 was amended 
and implemented, which regulates extracurricular activities in schools that are registered and funded by the Ministry of Education and Science. These schools are obliged when organizing and conducting the training and competition activities of children and students outside the curriculum in the institutions, in the system of preschool and school education to comply with the relevant ordinance, which states that "Training and competition activities are voluntary and related to development of the interests, abilities and needs in the field of physical activity, physical education, sports and sports-tourist activity, promotion of a healthy lifestyle, development and improvement of sportstechnical skills, selection of sports talents and creation of opportunities for performance in the field of sports. The training and competitive activity of children and students outside the curriculum is carried out by pedagogical specialists with professional qualification "teacher of physical education and sports" or "coach" by type of sport." The training activity includes planned activities by type of sport or other sports and sports-tourist activities for the school year and these activities must be carried out in the available sports base of the school. This regulation affects schools that are entirely state-funded. In the case of private schools funded by the Public Funding Program for Children and Students in Private Schools from 2017, public funding is paid for each child, but it is a challenge for most private schools to meet the requirements of the regulations. There are also schools in the education system of Bulgaria that are neither private nor attached to the Ministry of Education. They are foreign schools in Bulgaria that are under the auspices of their embassies and their education system (e.g. French Lyceum, Anglo-American School, Russian School, American College and others). They employ highly qualified teachers selected from the education system of the respective country, who teach in the official language of the particular school French, English, German, etc. There are also many Bulgarian teachers at these schools, who are appointed on the basis of very precise selection criteria and high competence. In these schools the calendar and curriculum of the respective educational system to which the specific school belongs are observed. In this type of school, extracurricular activities are widespread. The activities are extremely diverse, and they most often include activities such as sports, creative, educational and entertaining classes. They are consistent with the concept of holistic education, which prepares students for all aspects of life after graduation. Physical education is an integral part of the general education of each person. Sports activities are widespread, as it is well known that most European countries, and especially the United States, believe that competitive spirit is crucial in many professional fields, as well as teamwork, which is imperceptibly developing in most sports. Sport educates children of perseverance, determination, discipline, organization, tolerance and fair play. These are qualities and virtues that sport can permanently form and strengthen as a conscious benefit. When attending this type of activity, parents are confident that their children are using their free time properly, that they are playing sports and learning new things and acquiring new skills. In this type of school there is a great variety of sports activities - football, basketball, volleyball, 
athletics, swimming, climbing, gymnastics, various martial arts and dancing. Unlike the extracurricular activities that take place in the schools of the Ministry of Education and Science, in these schools it is possible to use not only the available material base but also an external sports base, as the children move with organized transport from the school. The pedagogues who conduct sports activities in this type of schools on the territory of Bulgaria are highly qualified professionals, and most often they have received their higher education in National Sports Academy "Vasil Levski". They are obliged to conduct the classes in the official language of the respective school or in English. Unfortunately, the epidemic situation in the world and in Bulgaria necessitated the cessation of all these activities and we all had to completely change our way of life. This has mostly affected children who are accustomed to a certain regime and a fairly high level of physical activity. Returning to a somewhat normal life was a challenge for everyone, and adapting to new rules and measures is not for everyone. All this aroused our interest and gave direction to the present study.

\section{Methodology}

The aim of the present study is to examine the opinion of parents of children from the secondary education level regarding extracurricular activities in physical education and sports in the context of COVID-19.

The subject of research are the extracurricular sports activities in foreign language schools that are not part of the system of the Bulgarian Ministry of Education and Science.

The object of study are the activities conducted in the conditions of COVID-19.

Research methods are: review study of specialized literature and normative documents and survey method.

Questionnaire method. Parents of children participating in extracurricular activities were provided with a link to a survey that was anonymous and it was not mandatory. The questionnaire was provided in Bulgarian and English language. It contains 11 questions, 8 of which are closed type, 2 are with more than one option and 1 is an open type question. 39 parents responded to the survey.

Statistical analysis. The results were processed with SPSS 23, using frequency analysis by one-dimensional and two-dimensional frequency distribution and comparing the distribution of traits with the Pearson $\chi^{2}$ test.

\section{Analysis of the results}

From March 13, 2020 for 14 months extracurricular activities in all schools in Bulgaria were completely canceled due to the pandemic of COVID-19. With the relief of the emergency measures and the order of the Minister of Health, a very small part of the extracurricular sports activities was resumed from May 2021. The conditions are very strict and are observed by all teachers and students. For most of the sports, especially those that are held indoors or require the participation of more 
athletes, this has proved to be a rather difficult condition. Most of these schools have their own sports facilities, which enables the implementation and compliance with anti-epidemic measures. Priority is given to sports that are traditional for Englishspeaking countries and are introduced at all levels of their education system. Figure 1 shows a model of the structure of the education system in the United States, which compared to the Bulgarian education system has one-year difference in relation to the year of graduation. In Bulgaria, school starts at the age of 7, and secondary education is completed at the age of 19, while in the United States at the age of 18.

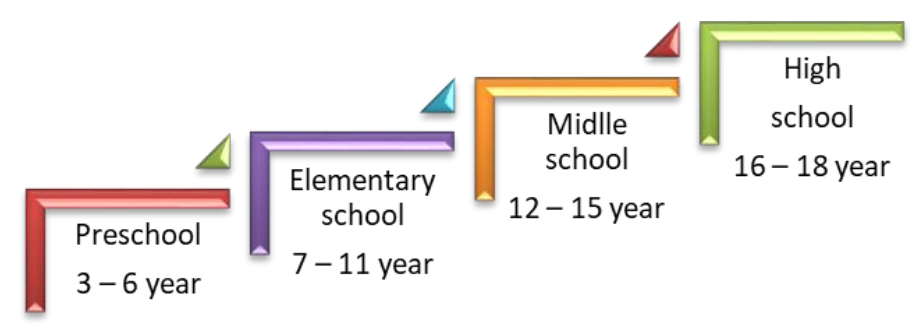

Figure 1. Structure of the education system in the United States

Figure 2 presents the most commonly used sports in extracurricular activities in foreign language schools in Bulgaria.

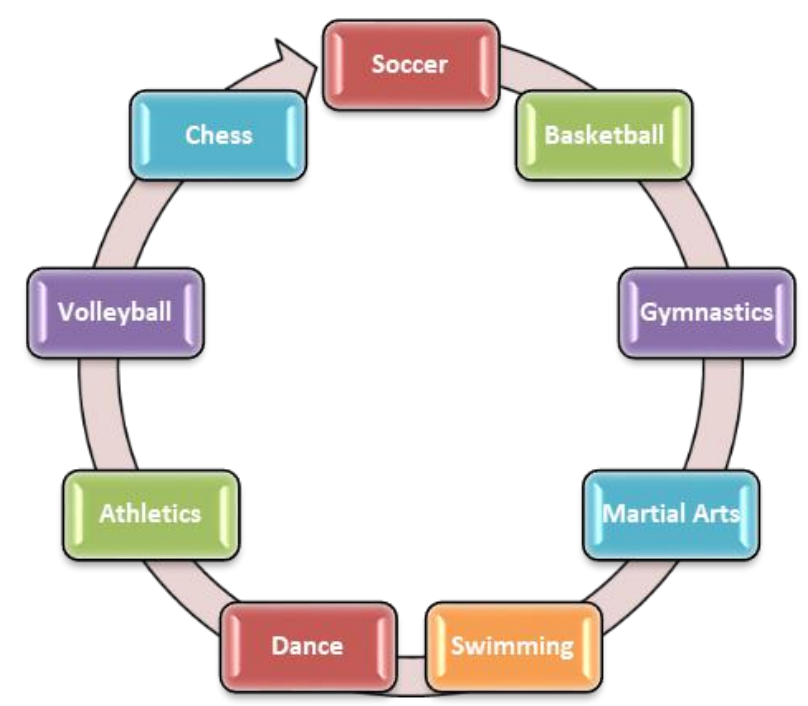

Figure 2. The most commonly used sports in extracurricular activities in foreign language schools 
After a study, we found that the most desirable among them are team sports such as football and basketball, followed by gymnastics and martial arts, followed by swimming, dancing, athletics, volleyball and chess. Figure 3 shows the percentage of children participating in extracurricular activities divided by gender, after the resumption of activities and in compliance with anti-epidemic measures. An analysis of the figure shows that most of the children are boys $-65 \%$, the remaining $35 \%$ are girls. The ratio does not differ from the ratio before the introduction of anti-epidemic measures for COVID-19.

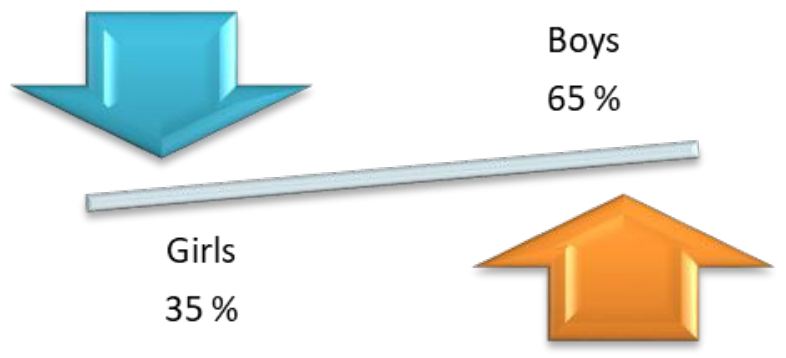

Figure 3. Percentage of children's participation in extracurricular sports activities in foreign language schools by gender factor

In the analysis of the results, the sequence of the answers from the survey was observed. To the question: "Do you approve of the resumption of extracurricular activities from May 10 , including sports?", $93.75 \%$ of parents approve of the resumption of activities, while the remaining $6.25 \%$ answered "rather yes", which is also a positive answer. Accordingly, the answers to the question: "Did your child/children resume attending extracurricular sports activities?" we received a 100\% answer "yes". It was important for us to find out if the parents approved of the fact that the classes were held only outdoors. The answers to this question are very interesting and are presented in Figure 4.

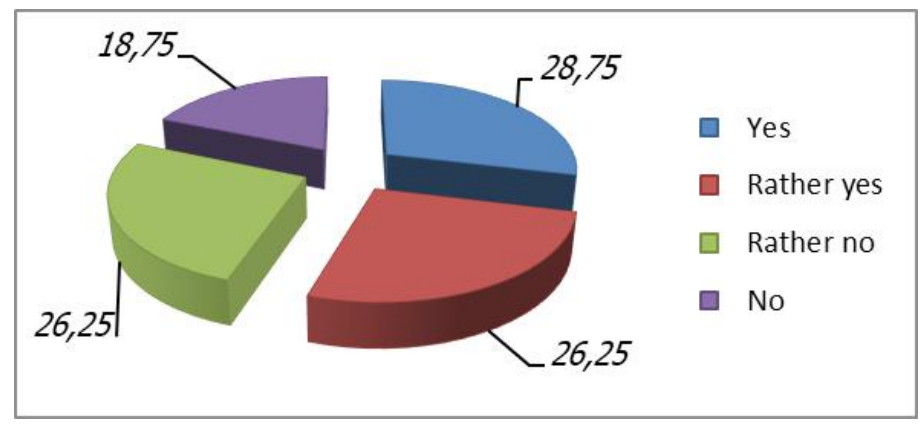

Figure 4. Distribution of the answers to the question: "Do you approve of the fact that the classes are held only outdoors?" 
An analysis of Figure 4 shows that the highest percentage of $28.5 \%$ of respondents strongly approve and $26.25 \%$ answered "rather yes", which is more than $50 \%$ positive. $18.7 \%$ disapprove of outdoor sports only, and $26.25 \%$ prefer to say "rather no". From this distribution of answers, it is evident that nearly $40 \%$ do not approve of conducting sports activities only outdoors.

To the question: "Does your child like to attend extracurricular activities involving sports", $100 \%$ answered yes, which shows that children willingly attend these activities and are not forced by their parents. To the question "Which activities does your child prefer to attend?", We provided the opportunity to indicate more than 1 answer. The results are presented in Figure 5. The figure shows that the favorite sport for children is basketball, 100\% of them have enrolled in it, followed by pottery class with $53.75 \%$ and football $48.75 \%$, the least preferred is Hip hop class $-25.00 \%$.

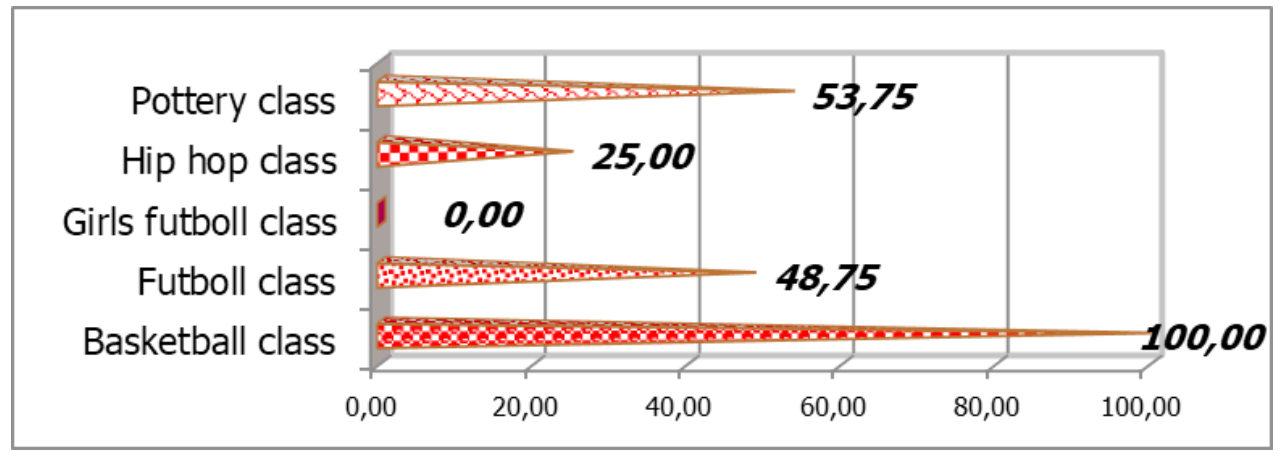

Figure 5. Percentage of answers to the question: "What activities does your child prefer to attend?

When conducting sports, the safety and security of children comes first, so we asked their parents: "Do you think that the measures imposed during the sports activities are sufficient to protect the health of the children?". The answer to this question shows that parents trust the teachers who work with their children in extracurricular activities and the measures introduced, because $93.75 \%$ believe that measures to protect children's health are sufficient, and $6.25 \%$ answered "rather yes", which is again a positive answer. The answers received to this question are also in support of the answers presented in Figure 5, which shows that children prefer sports like basketball, although it is a contact sport and it is almost impossible to keep a distance.

Given the requirements for keeping a distance to prevent possible infection, we asked the parents: "In your opinion, should the distance of $1.8 \mathrm{~m}$ be observed when conducting sports activities?". The answers to this question are presented in Figure 
6 and show that for $61 \%$ of the surveyed parents this measure is not necessary, for $33 \%$ it is "rather no", and "rather yes" for $6 \%$ of the parents.

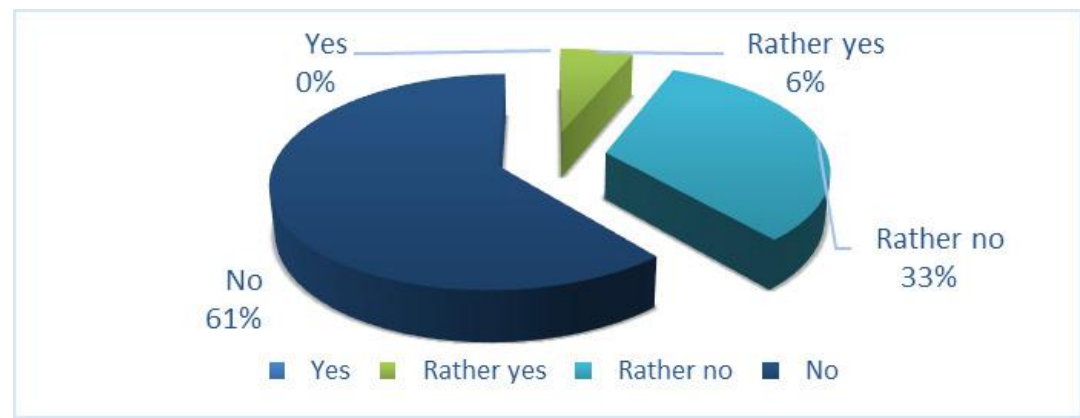

Figure 6. Percentage of answers to the question: In your opinion, should the distance of $1.8 \mathrm{~m}$ be observed when conducting sports activities?

The question: ЧIn your opinion, how does participation in extracurricular sports activities affect your child? $Ч$ was also given the opportunity for more than one answer. From Figure 7, the data show that $100 \%$ of parents believe that their children's level of physical fitness is improving. $90 \%$ of parents think that it is good for their children to spend more time with their friends outdoors. For $83.75 \%$ it is important for children to learn to follow rules and take responsibility when working in a team. For $73.75 \%$ of parents it is good for children to acquire new knowledge and skills about sports, and perhaps most important for parents $(83.75 \%)$ is that it gives their children the pleasure of practicing sports. None of the parents surveyed showed hesitation on this issue, which shows that they see the benefits of practicing sports, despite the epidemic measures.

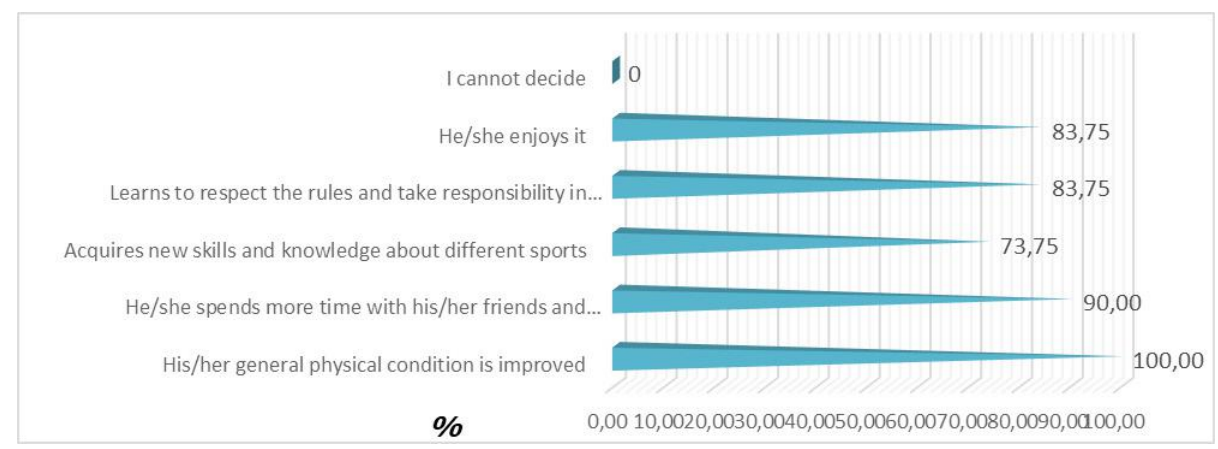

Figure 7. Percentage of answers to the question: „In your opinion, how does the participation in extracurricular sports activities affects your child?" 
The most important thing for the parents is the good health of the children and that is why we asked them: „,Do you think that the lack of extracurricular sports activities due to the epidemic situation has had a negative impact on the physical condition and health of your child/children?". Overall, all parents gave a positive answer $-100 \%$, with $87 \%$ answering yes and $13 \%$ answered "rather yes". Parents are the ones who support their children and do everything possible to create habits and educate them to a proper diet, love of sports and lay the foundations of a proper lifestyle. We were interested is the children's physical activity during the emergency measures, and we asked if the children practiced any physical activities during that time. (Figure 8).

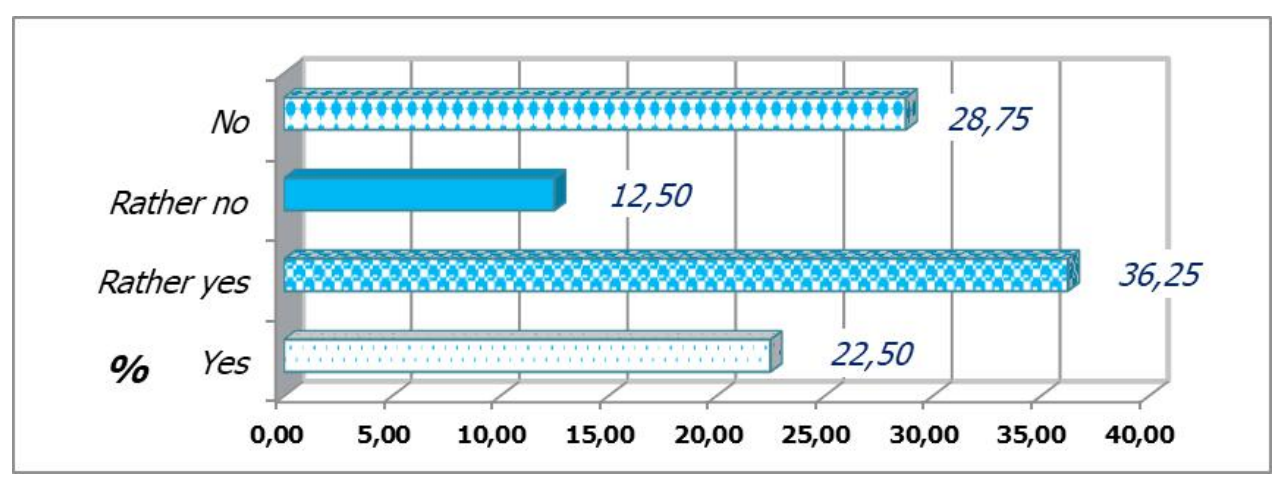

Figure 8. Percentage of answers to the question: Did your child / children maintain physical activity during the emergency measures?

The answers of the parents are not surprising, but confirm the expectations, as a positive answer was given by almost $60 \%$, with "Yes" answered $22.50 \%$, with "Rather yes" answered $36.25 \%$, categorically negative answer was given by $28.75 \%$, and $12.50 \%$ of the surveyed parents answered "Rather not".

During the emergency situation, the practice of sports in gyms, sports halls and swimming pools was forbidden. According to Kirilova and Andonov, (2019), children do not play sports mainly due to lack of desire, close and suitable place for it, and lack of training partner. So, it was interesting to find out how parents maintained their children's level of physical activity, so we asked them what activities they were most often involved in. The answers received show that parents have done everything possible to provide their children with the opportunity to maintain the level of physical activity. The activities that the children performed were cycling, rollerblading, horseback riding, running and walking in the mountains, basketball on a basket in front of the house, tennis and skiing during the season, as well as the implementation of a set of exercises by physical education and sports teachers to perform at home. 
For the purposes of the study, we compared the parents according to the criterion Bulgarians and foreigners to determine whether there is a difference between those given in the survey, but after applying the $\chi 2$ criterion of Pearson, we found no statistically significant difference on any of the questions.

\section{Discussion}

The presented facts and findings clearly support the thesis of the irreplaceable and socially significant presence of persistently organized physical activity in the life of modern man (respectively of students of all ages, realized in the physical education classes and especially in leisure time students). (Kinov 2014). In 2000, the International Federation of Physical Education (FIEP) approved a global Manifesto for Physical Education, which identifies the possibilities of targeted physical activity for an integrated impact on the younger generation and formulates a set of functions of physical education and sports, which can and must implement this activity as a component of modern educational systems. Also, the need for interaction of physical education with healthcare, rest (recreation), culture, tourism, sports is claimed in detail. Particular attention is paid to the provision of resources for physical education and sports (staff, sports facilities, equipment). As a continuation of this logical and natural direction in the development of physical education and sports worldwide is the agreement to provide quality physical education to students from around the world, implemented in 2003 by the International Council for Health, Physical Education, Recreation, Sports and dance (ICHPER-SD) for the preparation and adoption of World Standards for Physical Education in Schools. (Kinov 2014). These standards have been prepared with the assistance of UNESCO. They note that "... physical activity is an important part of human life and in this sense physical education is an integral part of the state educational process. It is extremely important to uphold the importance and status of physical education in schools around the world in the context of reduced school hours, violations of other subjects and activities, as well as interference in the quality of the physical education curriculum. Many opinion polls show that almost 3 out of 4 citizens of the European Union see sport as a way to support and promote integration, while two thirds see sport as a way to combat discrimination. [www.euractiv.com/]. The physical development and capacity of the young generation is closely linked to health status, health promotion and increased vitality. The formation of habits for regular exercise and sports is an investment with long-term social, health and economic effect (Borukova, Mavrudiev 2020).

\section{Conclusion}

A survey found that nearly $100 \%$ of the children of the surveyed parents like to play sports actively. A number of specialists recommend extra working in physical education classes (Tarnichkova and Petrova 2020) (Healthy People - Healthy People 
2020, 2021) and (Ivanov, 2019). When students are placed in new and different conditions for sports, their desire and interest to practice sports and to be active is not reduced. The created and well-organized safe environment during the classes gives confidence and peace of mind to the parents that their children are safe. In his research, Pan, (2020) makes the conclusion that due to the outbreak of COVID-19, individuals pay more attention to body health and realize the importance of doing exercises. We believe that the present study also confirms his conclusion.

In the school education system around the world, the main goal is to strengthen the health and vitality of students, as well as the formation of habits for regular exercise and sports. In the early childhood stage, the leading role is played by the parents, who in order to increase the motor activity of the children, they support them to get involved and try different sports. Thanks to long-term sports, children experience changes in the musculoskeletal system, complex development of physical qualities, increase the strength and mobility of nervous processes.

Acknowledgments. We would like to express our gratitude to all parents who voluntarily participated in the survey and confirmed that when conducting extracurricular activities and sports at school in the conditions of Covid-19 it is very important to have safe conditions and a safe environment for children.

\section{REFERENCES}

Anon, USNEI. Organization of U.S. Education. Available at: https://www2. ed.gov/about/offices/list/ous/international/usnei/us/edlite-org-us.html [Accessed June 7, 2021].

Borukova, M. \& Mavrudiev, P., 2020. Comparative analysis of the characteristics of physical ability of $14-15$ years old students. Trakia Journal of Sciences, 18(1), $830-836$.

Cdc.gov. 2021. Healthy People - Healthy People 2020. [online] Available at: <https://www.cdc.gov/nchs/healthy_people/hp2020.htm> [Accessed 20 May 2021].

Iancheva, T., Rogaleva, L., García-Mas, A. \& Olmedilla, A., 2020. Perfectionism, Mood States, And Coping Strategies of Sports Students from Bulgaria And Russia During the Pandemic Covid-19. Journal of Applied Sports Sciences, (1), 22 - 38.

Ivanov, V., 2019. Correlations Between Physical Education Training in The Final Years of High-School and Physical Education Training at University. Proceeding book, International Scientific Congress "Applied Sports Sciences", 452 - 456.

Kinov, S., 2014. Out of school activity in the system of physical education and sport (conception, content and forms for realisation). Dissertation. 
Kirilova, I. \& Andonov, St., 2019. Health factors - physical activity. Scientific and applied research conference. Book of proceedings, Sofia, $21-38$.

Kostov, K., 2005 Integrativnost I funkcii na fizicheskoto vuzpitanie $v$ nachalnoto uchilishte, Dissertation [in Bulgarian].

Pan, X., 2020. Exercise Under Death-Anxiety: Investigating Individual Exercise Psychology and Behavior from Perspective of Terror Management and Behavioral Immune System Introduction. Journal of Applied Sports Sciences, (1), 3 - 21.

Roach, E., 2021. Education in the United States of America. [online] WENR. Available at: https://wenr.wes.org/2018/06/education-in-theunited-states-of-america [Accessed 20 May 2021].

Tarnichkova, M. \& Petrova, M., 2020. Dynamics of Development and Evaluation of Agility in School Education (1st-12th Grade). Journal of Applied Sports Sciences, (2), $19-30$.

\section{Mariana Borukova}

https://orcid.org/0000-0003-4403-9065

Email: marianaborukova@gmail.com

$\triangle$ Milena Kuleva

https://orcid.org/0000-0002-6467-9644

National Sports Academy "Vassil Levski"

Sofia, Bulgaria

Email: milena.kuleva@nsa.bg 